\title{
Vanillin and 4-hydroxybenzyl alcohol promotes cell proliferation and neuroblast differentiation in the dentate gyrus of mice via the increase of brain-derived neurotrophic factor and tropomyosin-related kinase $B$
}

\author{
JEONG-HWI CHO $^{1 *}$, JOON HA PARK $^{1 *}$, JI HYEON AHN $^{1}$, JAE-CHUL LEE $^{1}$, IN KOO HWANG $^{2}$, \\ SEUNG MIN PARK ${ }^{3,4}$, JI YUN AHN ${ }^{3,4}$, DONG WON KIM ${ }^{3,5}$, JUN HWI CHO ${ }^{3}$, \\ JONG-DAI KIM $^{6}$, YOUNG-MYEONG KIM ${ }^{7}$, MOO-HO WON ${ }^{1}$ and IL-JUN KANG ${ }^{8}$
}

\footnotetext{
${ }^{1}$ Department of Neurobiology, School of Medicine, Kangwon National University, Chuncheon, Gangwon 200-701;

${ }^{2}$ Department of Anatomy and Cell Biology, College of Veterinary Medicine, Seoul National University, Seoul 151-742;

${ }^{3}$ Department of Emergency Medicine, School of Medicine, Kangwon National University, Chuncheon, Gangwon 200-701;

${ }^{4}$ Department of Emergency Medicine, Sacred Heart Hospital, College of Medicine, Hallym University, Anyang,

Gyeonggi 431-796; ${ }^{5}$ Department of Emergency Medicine, Chuncheon Sacred Heart Hospital, College of Medicine,

Hallym University, Chuncheon, Gangwon 200-702; ${ }^{6}$ Division of Food Biotechnology, School of Biotechnology;

${ }^{7}$ Department of Molecular and Cellular Biochemistry, School of Medicine, Kangwon National University,

Chuncheon, Gangwon 200-701; ${ }^{8}$ Department of Food Science and Nutrition,

Hallym University, Chuncheon, Gangwon 200-702, Republic of Korea
}

Received February 26, 2015; Accepted November 11, 2015

DOI: $10.3892 / \mathrm{mmr} .2016 .4915$

\begin{abstract}
Hydroxy-3-methoxybenzaldehyde (vanillin) and 4-hydroxybenzyl alcohol (4-HBA) are well-known phenolic compounds, which possess various therapeutic properties and are widely found in a variety of plants. In the present study, the effects of vanillin and 4-HBA were first investigated on cell proliferation, as well as neuronal differentiation and integration of granule cells in the dentate gyrus (DG) of adolescent mice using Ki-67, doublecortin (DCX) immunohistochemistry and 5-bromo-2'-deoxyuridine (BrdU)/feminizing Locus on X 3 (NeuN) double immunofluorescence. In both the vanillin and 4-HBA groups,
\end{abstract}

Correspondence to: Professor Moo-Ho Won, Department of Neurobiology, School of Medicine, Kangwon National University, 1 Kangwondaehak-gil, Chuncheon, Gangwon 200-701, Republic of Korea

E-mail: mhwon@kangwon.ac.kr

Professor Il-Jun Kang, Department of Food Science and Nutrition, Hallym University, 1 Hallymdaehak-gil, Chuncheon, Gangwon 200-702, Republic of Korea

E-mail: ijkang@hallym.ac.kr

*Contributed equally

Key words: 4-hydroxy-3-methoxybenzaldehyde, 4-hydroxybenzyl alcohol, neurogenesis, cell proliferation, neuroblast differentiation, brain-derived neurotrophic factor, tropomyosin-related kinase B the number of $\mathrm{Ki}-67^{+}$cells, $\mathrm{DCX}^{+}$neuroblasts and $\mathrm{BrdU}^{+} / \mathrm{NeuN}^{+}$ neurons were significantly increased in the subgranular zone of the DG, as compared with the vehicle group. In addition, the levels of brain-derived neurotrophic factor (BDNF) and tropomyosin-related kinase $\mathrm{B}$ (TrkB), a BDNF receptor, were significantly increased in the DG in the vanillin and 4-HBA groups compared with the vehicle group. These results indicated that vanillin and 4-HBA enhanced cell proliferation, neuroblast differentiation and integration of granule cells in the DG of adolescent mice . These neurogenic effects of vanillin and 4-HBA may be closely associated with increases in BDNF and TrkB.

\section{Introduction}

The hippocampus is a section of the forebrain, which is important in regulating emotionality and cognitive processes, including memory and learning $(1,2)$. Among the hippocampal subregions, the dentate gyrus (DG) grey matter is a well-known neurogenic region, and neural progenitor cells in the subgranular zone (SGZ) of the DG migrate into the granule cell layer and differentiate into mature granule cells (3-6). Newly formed granule cells in the DG are closely associated with memory and learning (2,7). In addition, it has been reported that neurogenesis in the hippocampus is influenced by numerous factors, including age, pathological conditions and pharmacological drugs (8-11). Furthermore, numerous studies have focused on neurogenesis in neurodegenerative diseases, and the stimulation of neurogenesis in neurogenic regions may be a potential therapeutic strategy for neurodegenerative diseases (12-15). 
4-Hydroxy-3-methoxybenzaldehyde (vanillin) and 4-hydroxybenzyl alcohol (4-HBA) are phenolic constituents found in various types of plants, including Gastrodia elata Blume (Orchidaceae) $(16,17)$. Previous studies have suggested that vanillin and 4-HBA have several therapeutic properties, including antioxidant, anti-inflammatory and anticancer properties (18-21). It has also been reported that vanillin and 4-HBA have a variety of beneficial effects against brain injury (22-24); however, few studies, to the best of our knowledge, regarding the effects of vanillin and 4-HBA on neurogenesis in the brain have been reported.

The present study first investigated the effects of vanillin and 4-HBA on cell proliferation and neuroblast differentiation in the DG using 5-bromo-2'-deoxyuridine (BrdU; an indicator for cell proliferation) labeling, Ki-67 (an endogenous marker for cell proliferation) and doublecortin (DCX; a marker for neuroblasts). In addition, the effects of the treatments on the expression of brain-derived neurotrophic factor (BDNF) and tropomyosin-related kinase $\mathrm{B}$ (TrkB, a BDNF receptor) in the DG of adolescent mice, since BDNF is known to be implicated in adult hippocampal neurogenesis through its primary receptor, TrkB $(25,26)$. The results of the present study may provide further information on the enhancement of neurogenesis, which is important as various neurological diseases are characterised by impaired neurogenesis.

\section{Materials and methods}

Experimental animals. A total of 42 male adolescent ICR mice, aged 8 weeks, were obtained from Orientbio, Inc. (Seongnam, South Korea) and used following 7 days of acclimation. The mice were housed in an atmosphere of $23^{\circ} \mathrm{C}$ and $60 \%$ humidity with a $12 \mathrm{~h}$ light/dark cycle and free access to food and water. The handling and caring of animals conformed to the National Institute of Health Guide for the Care and Use of Laboratory Animals (NIH Publication No. 85-23, 1985, revised 1996). The present study was approved by the Institutional Animal Care and Use Committee of Kangwon National University (KIACUC-12-0018). The utmost effort was made to minimize the number of animals used in the present study, as well as the suffering caused to them by the experiments performed.

Treatment with vanillin, 4-HBA and BrdU. The animals were divided into three groups ( $\mathrm{n}=14 /$ group): i) The vehicle-treated group (vehicle group); ii) the $40 \mathrm{mg} / \mathrm{kg}$ vanillin-treated group (vanillin group); iii) the $40 \mathrm{mg} / \mathrm{kg}$ 4-HBA-treated group (4-HBA group). Vanillin and 4-HBA were purchased from Sigma-Aldrich (St. Louis, MO, USA) and were prepared in $1 \mathrm{ml} 10 \%$ Tween-80 solution dissolved in normal saline. The experimental dosages of vanillin and 4-HBA were selected based on our previous study (22), and vehicle, vanillin and 4-HBA were administered orally using a feeding needle once daily for 28 days, due to the fact that DCX is exclusively expressed in immature neurons only between days 1-28 of cell age $(27,28)$. A $10 \%$ Tween-80 solution dissolved in normal saline was injected into the mice of the vehicle group. The animals were weighed twice weekly during drug treatment. No significant differences were observed in the body weight of mice in the experimental groups (data not shown). In order to label the dividing cells in the DG, all animals received an intraperitoneal injection of $50 \mathrm{mg} / \mathrm{kg}$ BrdU (Sigma-Aldrich) on days $8,15,22$ and 27 of the experiment, as described in our previous study $(29,30)$.

Tissue processing for histology. For histological analysis, the animals (n=7/group) were anesthetized with $30 \mathrm{mg} / \mathrm{kg}$ Zoletil 50 (Virbac, Carros, France) and perfused transcardially with $0.1 \mathrm{M}$ phosphate-buffered saline (PBS; pH 7.4), followed by $4 \%$ paraformaldehyde in $0.1 \mathrm{M}$ PBS. The brains were removed and post-fixed in the same fixative for $4 \mathrm{~h}$ at room temperature. The brain tissues were subsequently cryoprotected by infiltration with $30 \%$ sucrose overnight. The frozen tissues were serially sectioned on a cryostat (Leica, Wetzlar, Germany) into $30 \mu \mathrm{m}$ coronal sections and were subsequently collected into 6-well plates containing PBS for further analyses.

Immunohistochemistry. To obtain accurate data for immunohistochemistry, the tissue sections were carefully processed under identical conditions. The tissue sections were selected between -1.46 and $-2.46 \mathrm{~mm}$ posterior to the bregma in reference to the mouse atlas (31). The sections were sequentially treated with $0.3 \%$ hydrogen peroxide in PBS for $30 \mathrm{~min}$ at room temperature and $10 \%$ normal goat serum in $0.05 \mathrm{M}$ PBS for $30 \mathrm{~min}$ at room temperature. They were subsequently incubated with diluted polyclonal rabbit anti-Ki-67 (dilution, 1:100; cat. no. ab15580; Abcam, Cambridge, UK) or polyclonal goat anti-DCX (dilution, 1:100; cat. no. sc-8066; Santa Cruz Biotechnology, Inc., Santa Cruz, CA, USA) overnight at $4^{\circ} \mathrm{C}$. The sections were exposed to biotinylated goat anti-rabbit or rabbit anti-goat immunoglobulin $\mathrm{G}$ (IgG; dilution, 1:200; cat. no. BA-1000; Vector Laboratories Inc., Burlingame, CA, USA) and streptavidin peroxidase complex (dilution, 1:200; cat. no. SA-5004; Vector Laboratories Inc.). The abtibodies were visualized with 3,3'-diaminobenzidine tetrahydrochloride in $0.1 \mathrm{M}$ Tris-hydrochloride buffer and mounted on gelatin-coated slides. Following dehydration the sections were mounted in Canada balsam (Kanto Chemical Co., Inc., Tokyo, Japan).

Images of Ki-67 and DCX-immunoreactive structures were captured using an AxioM1 light microscope (BX53; Olympus, Tokyo, Japan) equipped with a digital camera (DP72; Olympus) connected to a personal computer monitor. The total number of $\mathrm{Ki}-67$ or DCX positive cells in all groups were counted in six sections/animal using an Image Analysis System equipped with a computer-based CCD camera (Optimas 6.5; CyberMetrics, Scottsdale, AZ, USA). The cell counts were obtained by averaging the counts from the tissue sections obtained from each animal.

Double immunofluorescence. Double immunofluorescence staining for BrdU and feminizing Locus on X 3 (NeuN) was performed in order to confirm the differentiation from newly generated cells to mature neurons. DNA denaturation was performed as follows: For BrdU immunostaining to visualize BrdU-labeled nuclei, the cells were incubated for $2 \mathrm{~h}$ in $50 \%$ formamide/2X SSC $(0.3 \mathrm{M} \mathrm{NaCl}$ and $0.03 \mathrm{M}$ sodium citrate) at $65^{\circ} \mathrm{C}$ and $30 \mathrm{~min}$ in $2 \mathrm{~N} \mathrm{HCl}$ at $37^{\circ} \mathrm{C}$, followed by rinsing for $10 \mathrm{~min}$ in $0.1 \mathrm{M}$ boric acid ( $\mathrm{pH} 8.5$ ). Following these steps, the tissue sections were incubated in 
the mixture of monoclonal rat anti-BrdU (dilution, 1:100; cat. no. MBS212468; BioSource International, Camarillo, CA, USA) and polyclonal rabbit anti-NeuN (dilution, 1:500; cat. no. ABN78; Chemicon International, Temecula, CA, USA) overnight at $4^{\circ} \mathrm{C}$. They were subsequently incubated in a mixture of fluorescein isothiocyanate-conjugated anti-rat IgG (dilution, 1:200; cat. no. 712-095-153; Jackson ImmunoResearch Labs, Inc., West Grove, PA, USA) and Cy3-conjugated anti-rabbit IgG (dilution, 1:500; cat. no. 711-165-152; Jackson ImmunoResearch Labs, Inc.) for $2 \mathrm{~h}$ at room temperature. The immunoreactions were observed under a confocal microscope (LSM 510 META NLO; Carl Zeiss, Jena, Germany). Cell counts were performed, as described above.

Western blot analysis. In order to examine the changes in the protein expression levels of DCX, BDNF and TrkB in the DG following vanillin or 4-HBA treatment for 28 days, 7 animals from each group were anesthetized with $30 \mathrm{mg} / \mathrm{kg}$ Zoletil 50 (Virbac, Carros, France), sacrificed by cervical dislocation, and used for western blot analysis, as described in our previous study (30). Briefly, following sacrifice by cervical dislocation, the mice were decapitated and the brains were removed. The brains were then serially and transversely cut into $400 \mu \mathrm{m}$ thick tissue sections using a vibratome (Leica Camera AG, Wetzlar, Germany). Subsequently, the DG was dissected using a surgical blade. The tissues were homogenized in $50 \mathrm{mM}$ PBS (pH 7.4) containing ethylene glycol tetraacetic acid ( $\mathrm{pH} 8.0), 0.2 \%$ NP-40, $10 \mathrm{mM}$ ethylenediaminetetraacetic acid ( $\mathrm{pH} 8.0), 15 \mathrm{mM}$ sodium pyrophosphate, $100 \mathrm{mM} \beta$-glycerophosphate, $50 \mathrm{mM}$ sodium fluoride, $150 \mathrm{mM} \mathrm{NaCl}, 2 \mathrm{mM}$ sodium orthvanadate, $1 \mathrm{mM}$ phenylmethylsulfonyl fluoride and $1 \mathrm{mM}$ dithiothreitol (DTT).

Following centrifugation at $16,000 \mathrm{x}$ g for $20 \mathrm{~min}$ at $4^{\circ} \mathrm{C}$, a Micro bicinchoninic acid Protein Assay kit with bovine serum albumin as a standard (Pierce Chemical, Rockford, IL,. USA) was used to determine the protein level in the supernatants. Aliquots containing $50 \mu \mathrm{g}$ total protein were boiled in loading buffer, which contained $250 \mathrm{mM}$ Tris ( $\mathrm{pH}$ 6.8), $10 \mathrm{mM}$ DTT, $10 \%$ sodium dodecyl sulfate, $0.5 \%$ bromophenol blue and $50 \%$ glycerol. The aliquots were subsequently loaded onto a $10 \%$ polyacrylamide gel (Sigma-Aldrich).

Following electrophoresis, the gels were transferred onto nitrocellulose membranes (Pall Corp., Pittsburgh, PA, USA). The same stripped nitrocellulose membranes were used to incubate all antibodies. In order to reduce background staining, the membranes were incubated with $5 \%$ non-fat dry milk in Tris buffered saline containing $0.1 \%$ Tween 20 for $45 \mathrm{~min}$. The membranes were subsequently incubated overnight at $4^{\circ} \mathrm{C}$ with polyclonal goat anti-DCX (dilution, 1:100; cat. no. sc-8066; Santa Cruz Biotechnology, Inc.), which produced a band at $\sim 40 \mathrm{kDa}$, polyclonal rabbit anti-BDNF (dilution, 1:500; cat. no. ab6200; Abcam), which produced a band at $\sim 28 \mathrm{kDa}$, and polyclonal rabbit anti-TrkB (dilution, 1:500; cat. no. sc-8316; Santa Cruz Biotechnology, Inc.), which produced two bands [truncated TrkB $(95 \mathrm{kDa})$ and full-length TrkB (145 kDa)]. The membranes were subsequently exposed to peroxidase-conjugated rabbit anti-goat (cat. no. sc-2768; dilution 1:5,000; Santa Cruz Biotechnology, Inc.) and goat anti-rabbit IgG (cat. no. sc-2004; dilution 1:5,000; Santa Cruz Biotechnology, Inc.) and an enhanced chemiluminescence kit (GE Healthcare Life Sciences, Chalfont, UK).
The result of the western blot analysis was scanned and densitometric analysis was performed for the quantification of the bands. Scion Image 4.0.2 software (Scion Corp., Frederick, MD, USA) was used to calculate the relative optical density (ROD): A ratio of the ROD was calibrated as \%, with the vehicle group designated as $100 \%$.

Statistical analysis. The data are presented as the mean \pm standard error. Statistical analysis of the differences between the groups was performed using one-way analysis of variance with Duncan's post-hoc test with SPPS software version 17.0 (SPSS, Inc., Chicago, IL, USA). $\mathrm{P}<0.05$ was considered to indicate a statistically significant difference.

\section{Results}

Changes in cell proliferation. Ki-67 positive (Ki-67+) cells were predominantly detected in the SGZ of the DG in all experimental groups (Fig. 1). In the vehicle group, numerous $\mathrm{Ki}-67^{+}$cells were observed in the SGZ (Fig. 1A). In both the vanillin and $4-\mathrm{HBA}$ groups, the number of $\mathrm{Ki}-67^{+}$cells was significantly increased compared with the vehicle group; however, no significant differences were identified in the distribution and number of $\mathrm{Ki}-67^{+}$cells between the vanillin and 4-HBA groups (Fig. 1B-D).

Changes in neuroblast differentiation. In all experimental groups, $\mathrm{DCX}^{+}$neuroblasts were predominantly detected in the SGZ of the DG (Fig. 2). In the vehicle group, numerous $\mathrm{DCX}^{+}$neuroblasts were observed in the SGZ, some with poorly-developed and others with well-developed dendrites with tertiary branches, which extended into the molecular layer of the DG (Fig. 2A and D). The number of $\mathrm{DCX}^{+}$neuroblasts was significantly increased in both the vanillin and 4-HBA groups, as compared with the vehicle group, although no significant differences were observed in the number of $\mathrm{DCX}^{+}$neuroblasts between the vanillin and 4-HBA groups (Fig. 2B-D). In addition, the dendrites of $\mathrm{DCX}^{+}$neuroblasts in the vanillin and 4-HBA groups were considerably long and thick compared with the ones in the vehicle group (Fig. 2B and C).

$\mathrm{BrdU}^{+} / \mathrm{NeuN} \mathrm{N}^{+}$neurons. In all experimental groups, newly generated $\mathrm{BrdU}^{+}$neurons with $\mathrm{NeuN}$ immunoreactivity were detected in the SGZ and granular cell layer of the DG (Fig. 3). In the vanillin and 4-HBA groups, the number of $\mathrm{BrdU}^{+} / \mathrm{NeuN}^{+}$ neurons was revealed to be significantly increased ( 2 -fold) compared with that in the vehicle group (Fig. 3).

Changes in the protein expression levels of DCX, BDNF and TrkB. In the present study, changes in the protein expression levels of DCX, BDNF and TrkB (full-length and truncated forms) were examined in the DG by western blot analysis (Fig. 4). In both the vanillin and 4-HBA groups, the protein levels of DCX ( 1.7-fold in the vanillin and $~ 2$-fold in 4-HBA group), BDNF ( 1.5-fold in each group) and full-length TrkB $(\sim 1.5$-fold in each group) were significantly increased compared with those in the vehicle group; however, no significant differences were observed in the protein expression of truncated TrkB, a dominant negative inhibitor of BDNF signaling via 

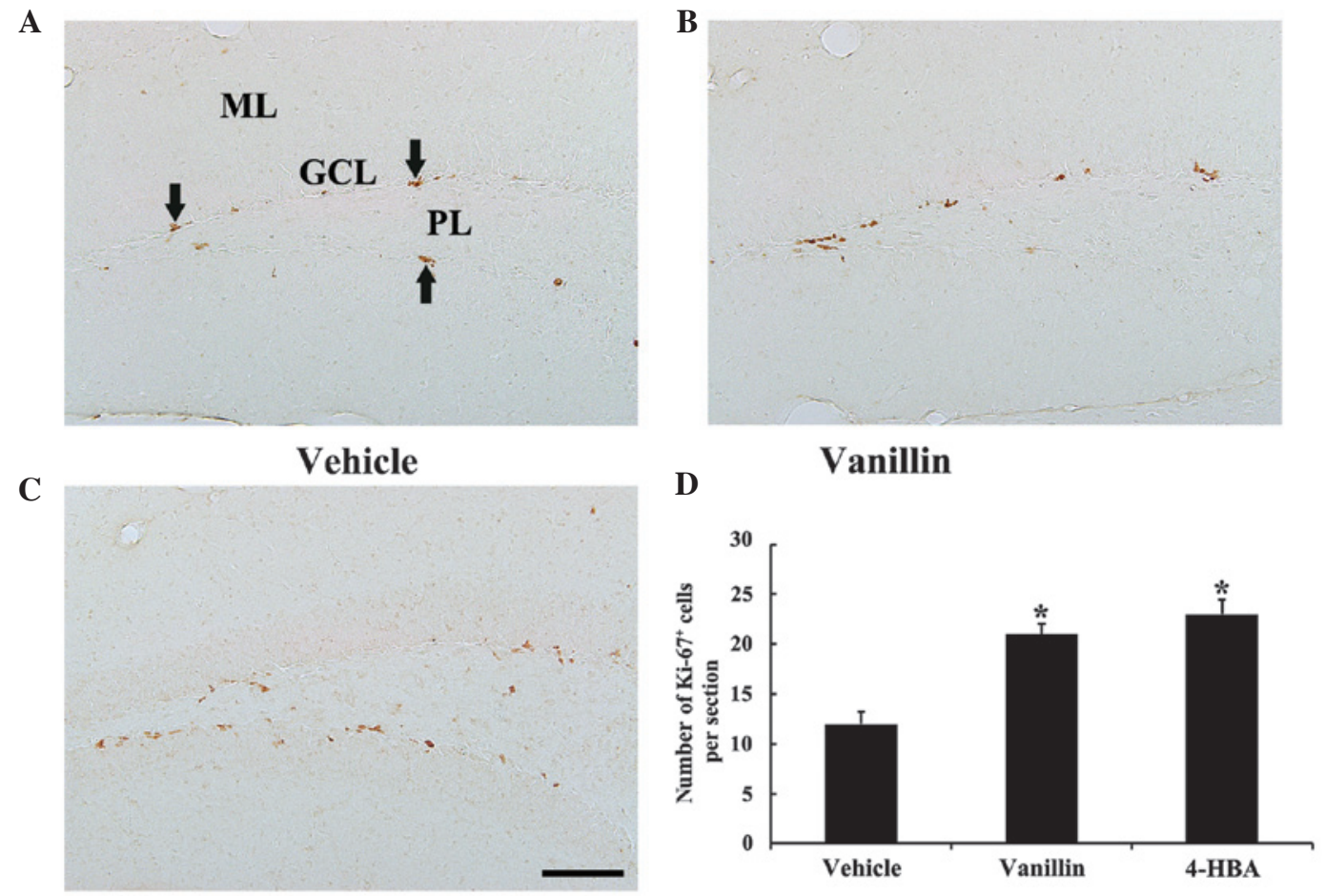

4-HBA

Figure 1. Immunohistochemistry for Ki-67 in the DG of the (A) vehicle, (B) vanillin and (C) 4-HBA groups. Ki-67+cells (arrows) were easily observed in the vehicle group. Ki-67+ cells in the vanillin and 4-HBA groups were more abundant compared with the vehicle group. (Scale bar, $100 \mu \mathrm{m}$ ). (D) The mean number of Ki- $67^{+}$cells per section in the DG in the vehicle, vanillin and 4-HBA groups were calculated. The data are presented as the mean \pm standard error ( $\mathrm{n}=7$ /group; "P<0.05, vs. the vehicle group). ML, molecular layer; GCL, granule cell layer; PL, polymorphic layer; DCX, doublecortin; DG, dentate gyrus; HBA, hydroxybenzyl alcohol; vanillin, 4-hydroxy-3-methoxybenzaldehyde.

$\mathbf{A}$

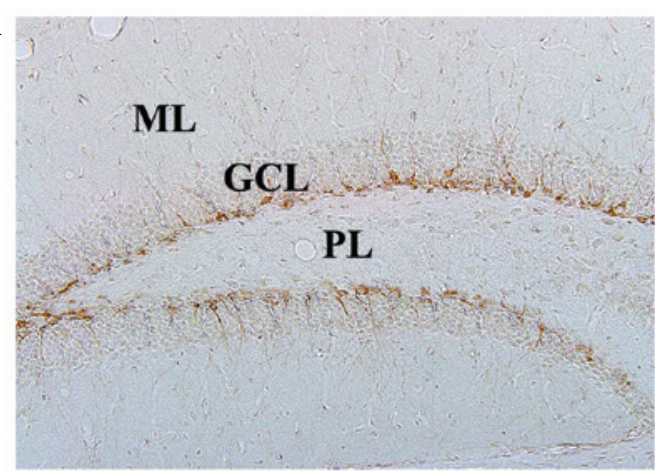

Vehicle

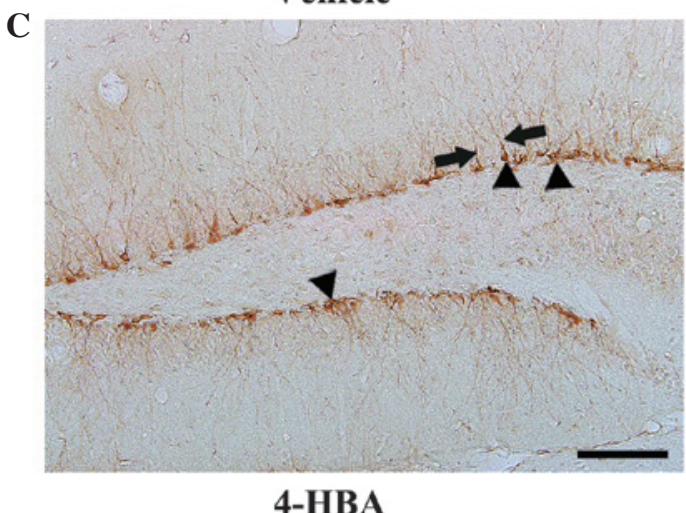

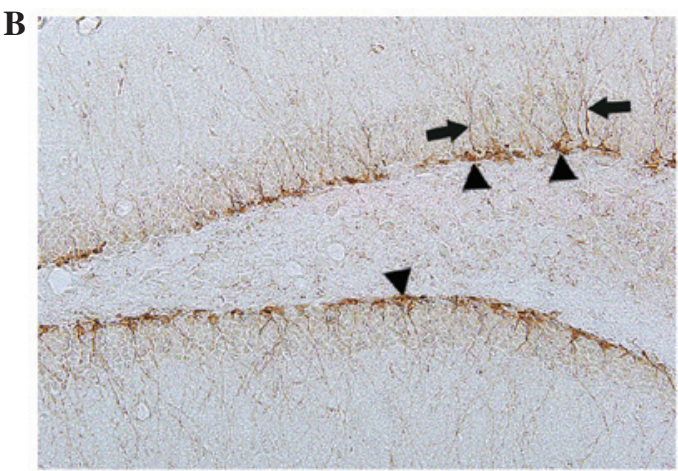

Vanillin

D

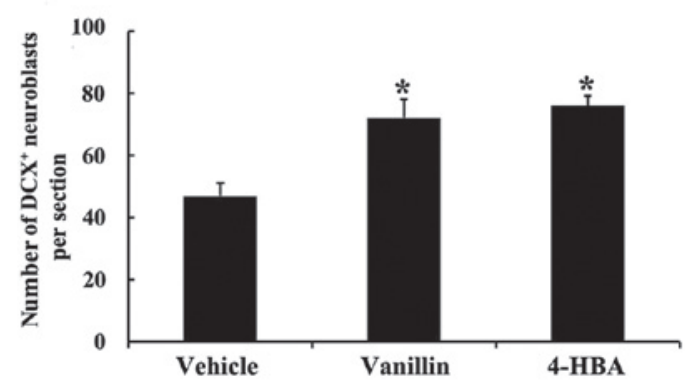

Figure 2. Immunohistochemistry for DCX in the DG of the (A) vehicle, (B) vanillin and (C) 4-HBA groups. In the vanillin and 4-HBA groups, the number of $\mathrm{DCX}^{+}$neuroblasts (arrowheads) was significantly increased, and their dendrites (arrows) were considerably longer and thicker compared with the vehicle control group. (Scale bar, $100 \mu \mathrm{m}$ ). (D) The mean number of DCX+ neuroblasts per section in the DG of the vehicle, vanillin and 4-HBA groups were calculated. The data are expressed as the mean \pm standard error ( $\mathrm{n}=7 /$ group; " $\mathrm{P}<0.05$, vs. the vehicle group). ML, molecular layer; GCL, granule cell layer; PL, polymorphic layer; DCX, doublecortin; DG, dentate gyrus; HBA, hydroxybenzyl alcohol; vanillin, 4-hydroxy-3-methoxybenzaldehyde. 

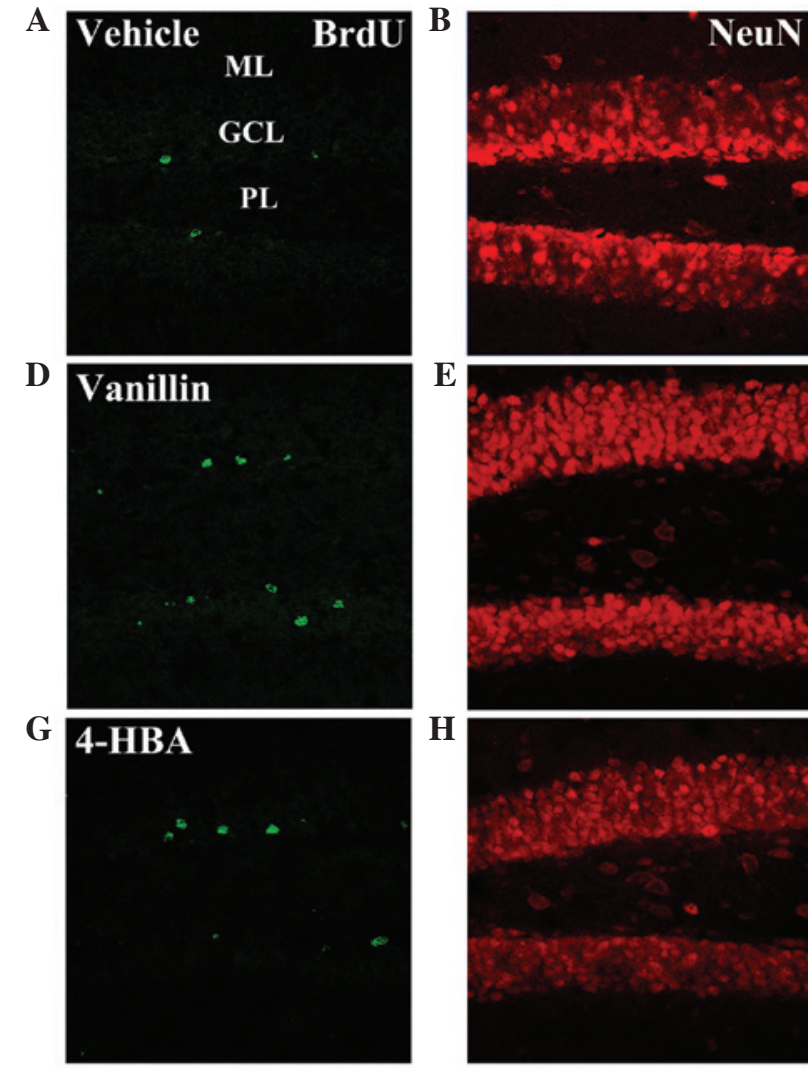

E

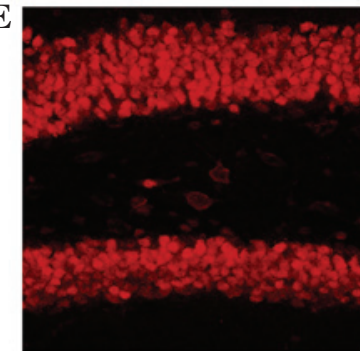

H
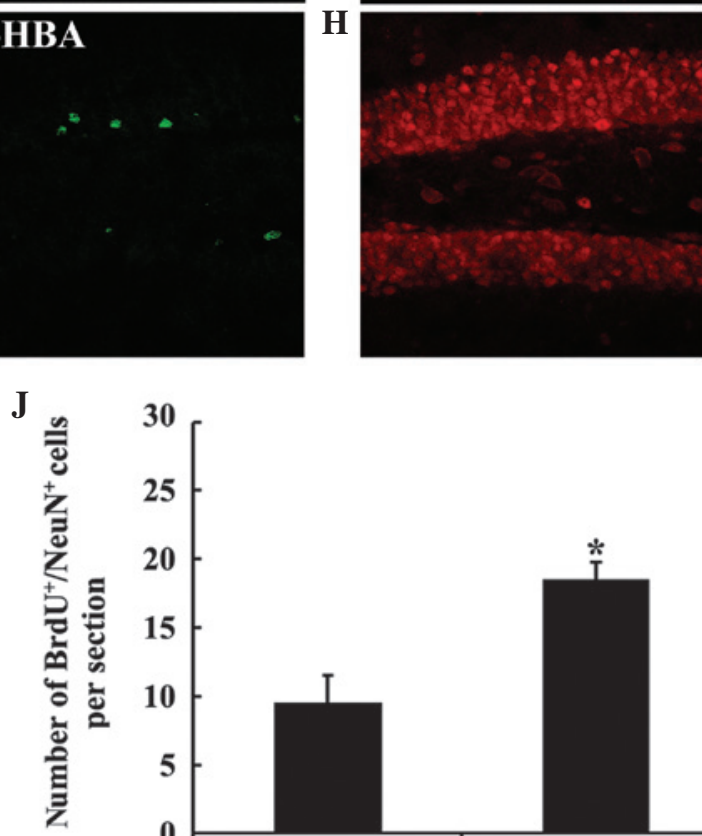

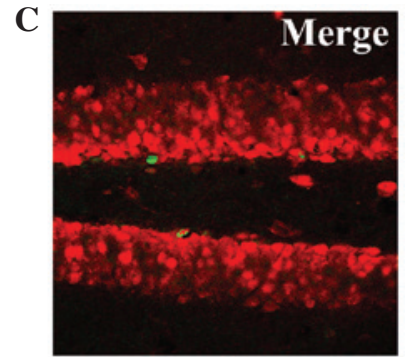

F

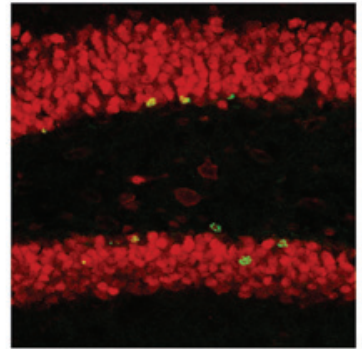

I

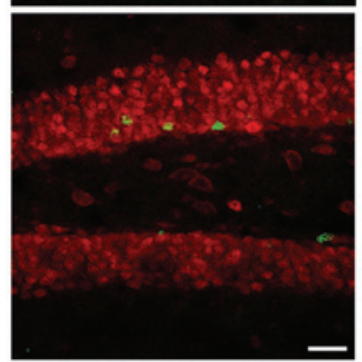

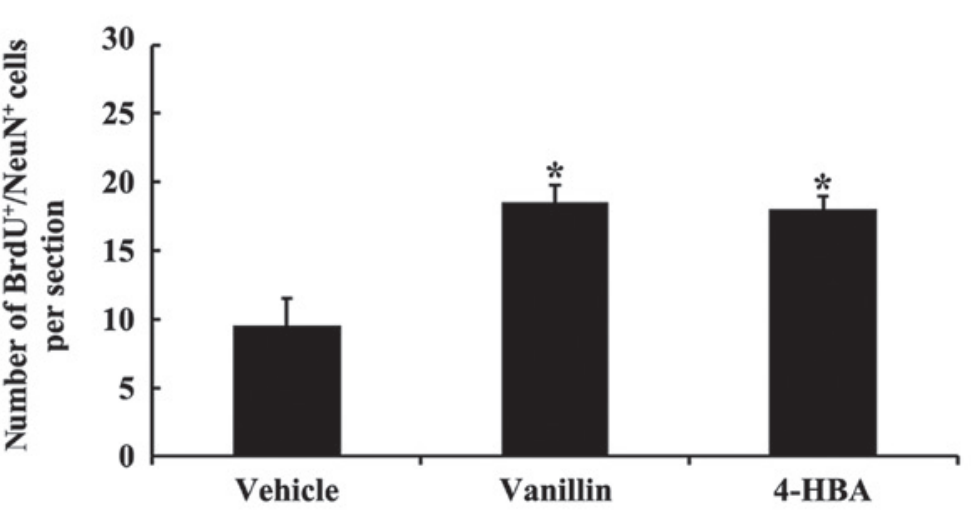

Figure 3. (A-I) Confocal images of cells double-labeled with BrdU (green; A, D and G), NeuN (red; B, E and H) and merged images (C, F and I) in the DG of the (A-C) vehicle, (D-F) vanillin and (G-I) 4-HBA groups. In the vanillin and 4-HBA groups, the number of BrdU $/ \mathrm{NeuN}^{+}$neurons were significantly increased compared with the vehicle group. (Scale bar, $40 \mu \mathrm{m}$ ). (J) The mean number of BrdU $\mathrm{N}^{+} \mathrm{NeuN}^{+}$neurons per section in the DG of the vehicle, vanillin and 4-HBA groups. The data are presented as the mean \pm standard error ( $\mathrm{n}=7 /$ group; ${ }^{\mathrm{P}}<0.05$, vs. the vehicle group). ML, molecular layer; GCL, granule cell layer; PL, polymorphic layer; DG, dentate gyrus; HBA, hydroxybenzyl alcohol; vanillin, 4-hydroxy-3-methoxybenzaldehyde; BrdU, 5-bromo-2'-deoxyuridine; NeuN, feminizing Locus on X 3 .

full-length TrkB (32), between the vanillin or 4-HBA, and the vehicle groups.

\section{Discussion}

Adult neurogenesis in the DG is considered to have an important role in hippocampal functions associated with learning and memory (7). It is well-known that the suppression of neurogenesis in the DG by aging or treatments with certain pharmacological drugs leads to an impairment of the hippocampus-dependent memory $(33,34)$. By contrast, numerous previous studies have reported that neurogenesis in the DG is increased in response to environmental conditions, including exercise, dietary energy restrictions and environmental enrichment, and that enhanced neurogenesis may improve learning and memory $(1,27,35,36)$.

In the present study, the effects of vanillin and 4-HBA treatments on cell proliferation and neuroblast differentiation in the SGZ of the DG in adolescent mice were first examined. The results revealed that the number of $\mathrm{Ki}-67^{+}$cells and $\mathrm{DCX}^{+}$ neuroblasts were significantly increased in both the vanillin and 4-HBA groups compared with the vehicle group. In addition, the number of $\mathrm{BrdU}^{+} / \mathrm{NeuN}^{+}$double-labeled granule cells was significantly increased in both the vanillin and 4-HBA groups. This finding was consistent with the findings of previous studies showing that treatments with phenolic compounds found in plants, including curcumin and (-)-epigallocatechin-3-gallate, increased neurogenesis in the hippocampus of adult mice $(37,38)$. 
A
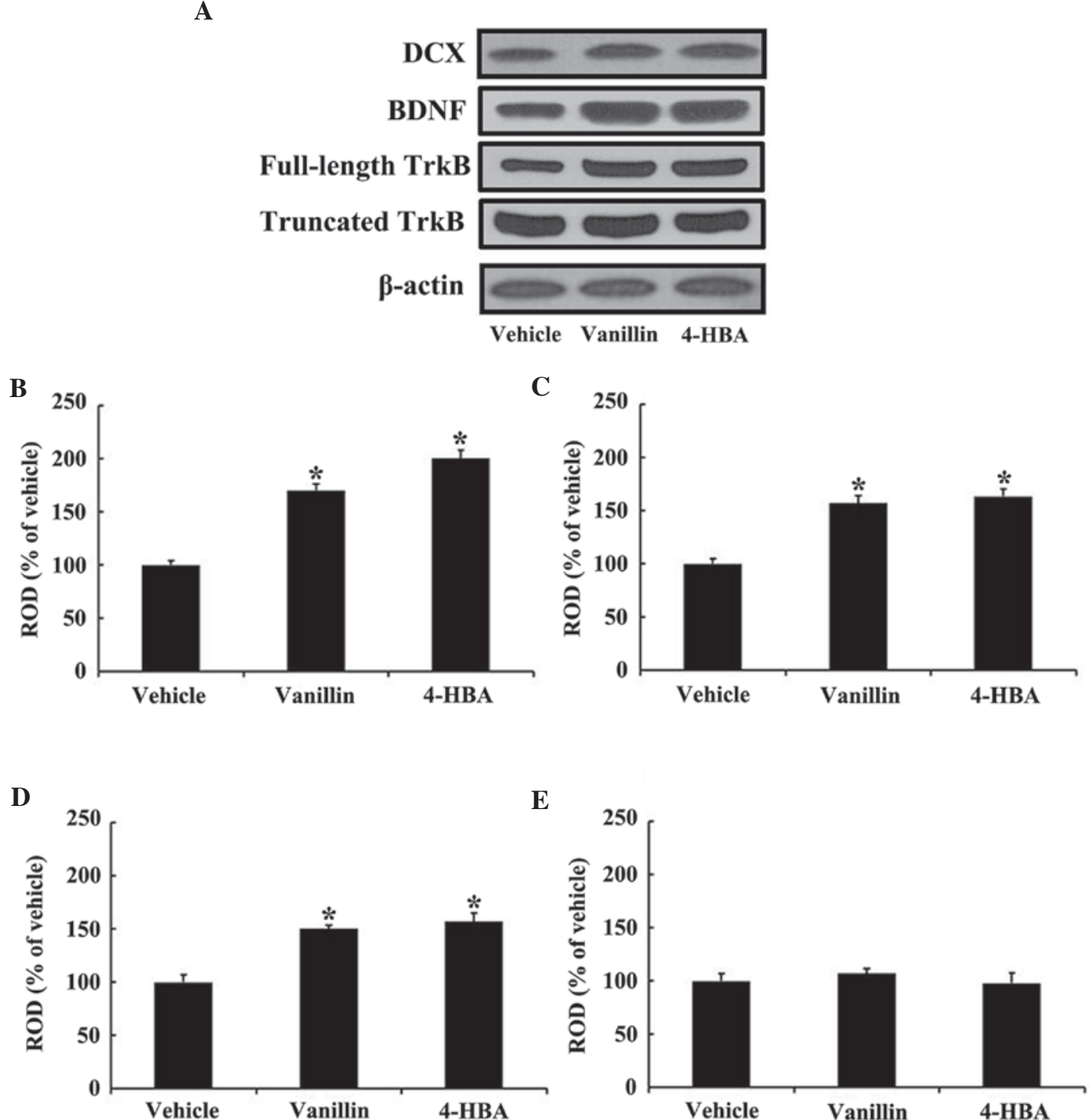

Figure 4. Western blot analysis of (A) the expression levels of DCX, BDNF and TrkB (full-length and truncated forms) in the DG of the vehicle, vanillin and 4-HBA groups. ROD, as percentage of the immunoblot band is shown for (B) DCX, (C) BDNF, (D) full-length TrkB, and (E) truncated TrkB. The data are presented as the mean \pm standard error ( $n=7$ per group; " $\mathrm{P}<0.05$, vs. the vehicle group). ROD, relative optical density; $\mathrm{DCX}$, doublecortin; $\mathrm{BDNF}$, brain-derived neurotrophic factor; TrkB, tropomyosin-related kinase B; HBA, hydroxybenzyl alcohol; vanillin, 4-hydroxy-3-methoxybenzaldehyde.

It has been previously reported that adult hippocampal neurogenesis is regulated by various growth factors, including $\operatorname{BDNF}(39,40)$. BDNF is a member of the neurotrophin family, which is involved in neuronal survival and plasticity and exerts its effects by binding to the $\operatorname{TrkB}$, which regulates the survival and differentiation of neurons and synaptic plasticity of the central nervous system (41-43). In order to explain the increased neurogenesis following vanillin and 4-HBA treatments, the present study investigated the alterations in the protein expression levels of BDNF and TrkB in the DG. It was revealed that, in both the vanillin and 4-HBA groups, the expression levels of BDNF and TrkB were markedly increased in the DG, as compared with the vehicle group. BDNF is known to influence the developmental processes of the brain $(44,45)$. Scharfman et al $(40)$ reported that administration of BDNF significantly increased neurogenesis in the DG of rats, whereas other previous studies reported that the knockdown of BDNF reduced neurogenesis in the DG of both adult rats and mice $(35,46)$. In addition, it was previously shown that BDNF-TrkB signaling is closely associated with hippocampal neurogenesis $(25,26)$. Sairanen et al (47) reported that a decrease in the protein expression of BDNF or TrkB activity causes reductions in neurogenesis in the mouse DG. Furthermore, it was previously shown that exercise-induced increases in the expression of BDNF and TrkB in the hippocampus were associated with the increase in cell proliferation in the hippocampal DG (48).

The results of the present study revealed that cell proliferation, as well as neuroblast differentiation and integration into granule cells, were markedly increased in the DG of adolescent mice treated with vanillin or 4-HBA. In addition, the expression levels of BDNF and TrkB were found to be significantly increased by vanillin or 4-HBA treatment, indicating that vanillin and 4-HBA enhanced cell proliferation, neuroblast differentiation and integration of granule cells in the DG of adolescent mice. These neurogenic effects of vanillin and 4-HBA may be closely associated with increases in BDNF and TrkB. Based on these findings, it was hypothesized 
that vanillin and 4-HBA have high therapeutic potential for the prevention and treatment of neurological disorders that involve impaired neurogenesis, including depression (49) and Alzheimer's disease (50).

\section{Acknowledgements}

The authors would like to thank Mr. Seung Uk Lee (Department of Neurobiology, School of Medicine, Kangwon National University, Chuncheon, South Korea) for his technical assistance in the present study. The present study was supported by the Basic Science Research Program of the National Research Foundation of Korea funded by the Ministry of Science, ICT and future Planning (grant no. NRF-2013R1A2A2A01068190), and by the National Research Foundation of Korea (grant no. NRF-2013M3A9B6046563), which was funded by the Ministry of Science, ICT, and Future Planning.

\section{References}

1. Sahay A, Scobie KN, Hill AS, O'Carroll CM, Kheirbek MA, Burghardt NS, Fenton AA, Dranovsky A and Hen R: Increasing adult hippocampal neurogenesis is sufficient to improve pattern separation. Nature 472: 466-470, 2011.

2. Shimazu K, Zhao M, Sakata K, Akbarian S, Bates B, Jaenisch R and Lu B: NT-3 facilitates hippocampal plasticity and learning and memory by regulating neurogenesis. Learn Mem 13: 307-315, 2006.

3. Kempermann G: The neurogenic reserve hypothesis: What is adult hippocampal neurogenesis good for? Trends Neurosci 31: 163-169, 2008.

4. Li H, Lee CH, Yoo KY, Choi JH, Park OK, Yan BC, Byun K, Lee B, Hwang IK and Won MH: Chronic treatment of exendin-4 affects cell proliferation and neuroblast differentiation in the adult mouse hippocampal dentate gyrus. Neurosci Lett 486: 38-42, 2010.

5. Hong J, Wu G, Zou Y, Tao J and Chen L: Electroacupuncture promotes neurological functional recovery via the retinoic acid signaling pathway in rats following cerebral ischemia-reperfusion injury. Int J Mol Med 31: 225-231, 2013.

6. Zhang L, Yan R, Zhang Q, Wang H, Kang X, Li J, Yang S, Zhang J, Liu Z and Yang X: Survivin, a key component of the Wnt/ $\beta$-catenin signaling pathway, contributes to traumatic brain injury-induced adult neurogenesis in the mouse dentate gyrus. Int J Mol Med 32: 867-875, 2013.

7. Bruel-Jungerman E, Rampon C and Laroche S: Adult hippocampal neurogenesis, synaptic plasticity and memory: Facts and hypotheses. Rev Neurosci 18: 93-114, 2007.

8. Hwang IK, Yi SS, Song W, Won MH, Yoon YS and Seong JK: Effects of age and treadmill exercise in chronic diabetic stages on neuroblast differentiation in a rat model of type 2 diabetes. Brain Res 1341: 63-71, 2010.

9. Feng X, Xing J, Feng G, Sang A, Shen B, Xu Y, Jiang J, Liu S, Tan W, Gu Z and Li L: Age-dependent impaired neurogenic differentiation capacity of dental stem cell is associated with Wnt/ $\beta$-catenin signaling. Cell Mol Neurobiol 33: 1023-1031, 2013.

10. Niu Y, Li Y, Zang J, Huang H, Deng J, Cui Z, Yu D and Deng J: Death receptor 5 and neuroproliferation. Cell Mol Neurobiol 32: 255-265, 2012.

11. Zhang XY, Yang YJ, Xu PR, Zheng XR, Wang QH, Chen CF and Yao Y: The role of $\beta$-catenin signaling pathway on proliferation of rats neural stem cells after hyperbaric oxygen therapy in vitro. Cell Mol Neurobiol 31: 101-109, 2011.

12. Fuster-Matanzo A, Llorens-Martin M, Hernández F and Avila J: Role of neuroinflammation in adult neurogenesis and Alzheimer disease: Therapeutic approaches. Mediators Inflamm 2013: 260925, 2013.

13. O'Sullivan SS, Johnson M, Williams DR, Revesz T, Holton JL, Lees AJ and Perry EK: The effect of drug treatment on neurogenesis in parkinson's disease. Mov Disord 26: 45-50, 2011

14. Garcez RC, Teixeira BL, Schmitt Sdos S, Alvarez-Silva M and Trentin AG: Epidermal growth factor (EGF) promotes the in vitro differentiation of neural crest cells to neurons and melanocytes. Cell Mol Neurobiol 29: 1087-1091, 2009.
15. He N, Wang Z, Wang Y, Shen H and Yin M: ZY-1, a novel nicotinic analog, promotes proliferation and migration of adult hippocampal neural stem/progenitor cells. Cell Mol Neurobiol 33: 1149-1157, 2013.

16. Jung JW, Yoon BH, Oh HR, Ahn JH, Kim SY, Park SY and Ryu JH: Anxiolytic-like effects of Gastrodia elata and its phenolic constituents in mice. Biol Pharm Bull 29: 261-265, 2006.

17. Lee YS, Ha JH, Yong CS, Lee DU, Huh K, Kang YS, Lee SH, Jung MW and Kim JA: Inhibitory effects of constituents of Gastrodia elata B1. on glutamate-induced apoptosis in IMR-32 human neuroblastoma cells. Arch Pharm Res 22: 404-409, 1999.

18. Lim EJ, Kang HJ, Jung HJ and Park EH: Anti-angiogenic, anti-inflammatory and anti-nociceptive activity of 4-hydroxybenzyl alcohol. J Pharm Pharmacol 59: 1235-1240, 2007.

19. Lirdprapamongkol K, Sakurai H, Kawasaki N, Choo MK, Saitoh Y, Aozuka Y, Singhirunnusorn P, Ruchirawat S, Svasti J and Saiki I: Vanillin suppresses in vitro invasion and in vivo metastasis of mouse breast cancer cells. Eur J Pharm Sci 25: 57-65, 2005.

20. Liu J and Mori A: Antioxidant and pro-oxidant activities of p-hydroxybenzyl alcohol and vanillin: Effects on free radicals, brain peroxidation and degradation of benzoate, deoxyribose, amino acids and DNA. Neuropharmacology 32: 659-669, 1993.

21. MurakamiY,Hirata A,Ito S,Shoji M,TanakaS, Yasui T,Machino M and Fujisawa S: Re-evaluation of cyclooxygenase-2-inhibiting activity of vanillin and guaiacol in macrophages stimulated with lipopolysaccharide. Anticancer Res 27: 801-807, 2007.

22. Kim HJ, Hwang IK and Won MH: Vanillin, 4-hydroxybenzyl aldehyde and 4-hydroxybenzyl alcohol prevent hippocampal CA1 cell death following global ischemia. Brain Res 1181: 130-141, 2007.

23. Makni M, Chtourou Y, Barkallah M and Fetoui H: Protective effect of vanillin against carbon tetrachloride $\left(\mathrm{CCl}_{4}\right)$-induced oxidative brain injury in rats. Toxicol Ind Health 28: 655-662, 2012.

24. Yu SS, Zhao J, Lei SP, Lin XM, Wang LL and Zhao Y: 4-hydroxybenzyl alcohol ameliorates cerebral injury in rats by antioxidant action. Neurochem Res 36: 339-346, 2011.

25. Donovan MH, Yamaguchi M and Eisch AJ: Dynamic expression of TrkB receptor protein on proliferating and maturing cells in the adult mouse dentate gyrus. Hippocampus 18: 435-439, 2008.

26. Wu CW, Chang YT, Yu L, Chen HI, Jen CJ, Wu SY, Lo CP and Kuo YM: Exercise enhances the proliferation of neural stem cells and neurite growth and survival of neuronal progenitor cells in dentate gyrus of middle-aged mice. J Appl Physiol (1985) 105: $1585-1594,2008$

27. Brown J, Cooper-Kuhn CM, Kempermann G, Van Praag H, Winkler J, Gage FH and Kuhn HG: Enriched environment and physical activity stimulate hippocampal but not olfactory bulb neurogenesis. Eur J Neurosci 17: 2042-2046, 2003.

28. Couillard-Despres S, Winner B, Schaubeck S, Aigner R, Vroemen M, Weidner N, Bogdahn U, Winkler J, Kuhn HG and Aigner L: Doublecortin expression levels in adult brain reflect neurogenesis. Eur J Neurosci 21: 1-14, 2005.

29. Chen BH, Yan BC, Park JH, Ahn JH, Lee DH, Kim IH, Cho JH, Lee JC, Kim SK, Lee B, et al: Aripiprazole, an atypical antipsychotic drug, improves maturation and complexity of neuroblast dendrites in the mouse dentate gyrus via increasing superoxide dismutases. Neurochem Res 38: 1980-1988, 2013.

30. Lee TH, Lee CH, Kim IH, Yan BC, Park JH, Kwon SH, Park OK, Ahn JH, Cho JH, Won MH and Kim SK: Effects of ADHD therapeutic agents, methylphenidate and atomoxetine, on hippocampal neurogenesis in the adolescent mouse dentate gyrus. Neurosci Lett 524: 84-88, 2012.

31. Franklin KBJ and Paxinos G: The mouse brain in stereotaxic coordinates. Academic Press, San Diego, 1997.

32. Eide FF, Vining ER, Eide BL, Zang K, Wang XY and Reichardt LF: Naturally occurring truncated trkB receptors have dominant inhibitory effects on brain-derived neurotrophic factor signaling. J Neurosci 16: 3123-3129, 1996.

33. Kuhn HG, Dickinson-Anson H and Gage FH: Neurogenesis in the dentate gyrus of the adult rat: Age-related decrease of neuronal progenitor proliferation. J Neurosci 16: 2027-2033, 1996.

34. Shors TJ, Miesegaes G, Beylin A, Zhao M, Rydel T and Gould E: Neurogenesis in the adult is involved in the formation of trace memories. Nature 410: 372-376, 2001.

35. Lee J, Duan W and Mattson MP: Evidence that brain-derived neurotrophic factor is required for basal neurogenesis and mediates, in part, the enhancement of neurogenesis by dietary restriction in the hippocampus of adult mice. J Neurochem 82: 1367-1375, 2002. 
36. Nilsson M, Perfilieva E, Johansson U, Orwar O and Eriksson PS Enriched environment increases neurogenesis in the adult rat dentate gyrus and improves spatial memory. J Neurobiol 39: 569-578, 1999 .

37. Kim SJ, Son TG, Park HR, Park M, Kim MS, Kim HS, Chung HY, Mattson MP and Lee J: Curcumin stimulates proliferation of embryonic neural progenitor cells and neurogenesis in the adult hippocampus. J Biol Chem 283: 14497-14505, 2008.

38. Yoo KY, Choi JH, Hwang IK, Lee CH, Lee SO, Han SM, Shin HC, Kang IJ and Won MH: (-)-Epigallocatechin-3-gallate increases cell proliferation and neuroblasts in the subgranular zone of the dentate gyrus in adult mice. Phytother Res 24: 1065-1070, 2010.

39. Aberg MA, Aberg ND, Hedbäcker H, Oscarsson J and Eriksson PS: Peripheral infusion of IGF-I selectively induces neurogenesis in the adult rat hippocampus. J Neurosci 20: 2896-2903, 2000.

40. Scharfman H, Goodman J, Macleod A, Phani S, Antonelli C and Croll S: Increased neurogenesis and the ectopic granule cells after intrahippocampal BDNF infusion in adult rats. Exp Neurol 192: 348-356, 2005.

41. Huang EJ and Reichardt LF: Neurotrophins: Roles in neuronal development and function. Ann Rev Neurosci 24: 677-736, 2001

42. Kim SE, Ko IG, Kim BK, Shin MS, ChoS, Kim CJ,Kim SH, Baek SS, LeeEK and Jee YS: Treadmill exercise prevents aging-induced failure of memory through an increase in neurogenesis and suppression of apoptosis in rat hippocampus. Exp Gerontol 45: 357-365, 2010.

43. Lu Y, Christian K and Lu B: BDNF: A key regulator for protein synthesis-dependent LTP and long-term memory? Neurobiol Learn Mem 89: 312-323, 2008.
44. Bramham CR and Messaoudi E: BDNF function in adult synaptic plasticity: The synaptic consolidation hypothesis. Prog Neurobiol 76: 99-125, 2005.

45. Yoo DY, Nam SM, Kim W, Lee CH, Won MH, Hwang IK and Yoon YS: N-acetylserotonin increases cell proliferation and differentiating neuroblasts with tertiary dendrites through upregulation of brain-derived neurotrophic factor in the mouse dentate gyrus. J Vet Med Sci 73: 1411-1416, 2011.

46. Taliaz D, Stall N, Dar DE and Zangen A: Knockdown of brain-derived neurotrophic factor in specific brain sites precipitates behaviors associated with depression and reduces neurogenesis. Mol Psychiatry 15: 80-92, 2010.

47. Sairanen M, Lucas G, Ernfors P, Castrén M and Castrén E: Brain-derived neurotrophic factor and antidepressant drugs have different but coordinated effects on neuronal turnover, proliferation and survival in the adult dentate gyrus. J Neurosci 25: 1089-1094, 2005.

48. Heo YM, Shin MS, Kim SH, Kim TW, Baek SB and Baek SS: Treadmill exercise ameliorates disturbance of spatial learning ability in scopolamine-induced amnesia rats. J Exerc Rehabil 10: 155-161, 2014.

49. Schmidt HD and Duman RS: The role of neurotrophic factors in adult hippocampal neurogenesis, antidepressant treatments and animal models of depressive-like behavior. Behav Pharmacol 18: 391-418, 2007.

50. Haughey NJ, Nath A, Chan SL, Borchard AC, Rao MS and Mattson MP: Disruption of neurogenesis by amyloid beta-peptide and perturbed neural progenitor cell homeostasis, in models of Alzheimer's disease. J Neurochem 83: 1509-1524, 2002. 